\title{
Revisiting historical beech and oak forests in Indiana using a GIS method to recover information from bar charts
}

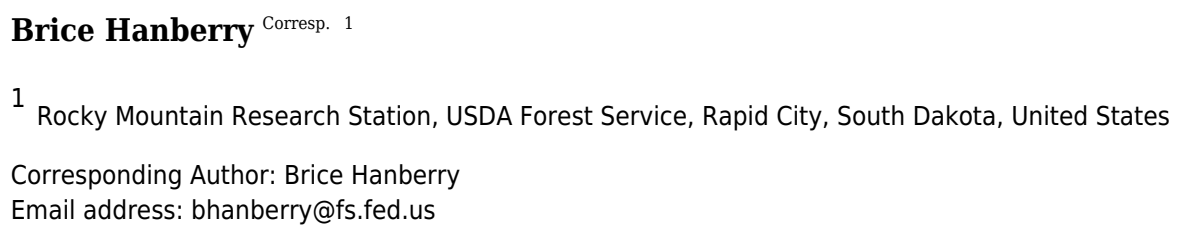

Historical GIS involves applying GIS to historical research. Using a unique method, I recovered historical tree survey information stored in bar chart figures of a 1956 publication. I converted PDF files to TIF files, which is a format for a GIS layer. I then employed GIS tools to measure lengths of each bar in the TIF file and used a regression ( $R^{2}$ $=97 \%$ ) to convert bar lengths to numerical values of tree composition. I joined this information to a spatial GIS layer of Indiana, USA. To validate results, I compared predictions against an independent dataset and written summaries. I determined that historically (circa 1799 to 1846 ) in Indiana, oaks were $27 \%$ of all trees, beech was $25 \%$, hickories and sugar maple were $7 \%$ each, and ash was $4.5 \%$. Beech forests dominated (i.e., $>24 \%$ of all trees) $44 \%$ of 8.9 million ha (i.e., where data were available in Indiana), oak forests dominated $29 \%$, beech and oak forests dominated $4.5 \%$, and oak savannas were in $6 \%$ of Indiana, resulting in beech and/or oak dominance in $84 \%$ of the state. This method may be valuable to reclaim information available in published figures, when associated raw data are not available. 
1 Revisiting historical beech and oak forests in Indiana using a GIS method to recover

2 information from bar charts

3

4

5 Brice B. Hanberry

6

$7 \quad{ }^{1}$ USDA Forest Service, Rocky Mountain Research Station, Rapid City, SD 57702 USA

8

9

10

11 e-mail: bhanberry@fs.fed.us

12

13

14

15

16

17

18

19

20

21

22

23 
24 Abstract Historical GIS involves applying GIS to historical research. Using a unique method, I

25 recovered historical tree survey information stored in bar chart figures of a 1956 publication. I

26

27

28

converted PDF files to TIF files, which is a format for a GIS layer. I then employed GIS tools to measure lengths of each bar in the TIF file and used a regression $\left(\mathrm{R}^{2}=97 \%\right)$ to convert bar lengths to numerical values of tree composition. I joined this information to a spatial GIS layer of Indiana, USA. To validate results, I compared predictions against an independent dataset, written summaries, and maps. I determined that historically (circa 1799 to 1846) in Indiana, oaks were $27 \%$ of all trees, beech was $25 \%$, hickories and sugar maple were $7 \%$ each, and ash was $4.5 \%$. Beech forests dominated (i.e., $>24 \%$ of all trees) $44 \%$ of 8.9 million ha (i.e., where data were available in Indiana), oak forests dominated 29\%, beech and oak forests dominated 4.5\%, and oak savannas were in $6 \%$ of Indiana, resulting in beech and/or oak dominance in $84 \%$ of the state. This method may be valuable to reclaim information available in published figures, when associated raw data are not available.

Introduction

Researchers increasingly are applying Geographical Information Systems (GIS) to a range of topics, including historical research (Gregory and Healey 2007). A variety of approaches are available, with more methods and tools continually under development. Currently, there is a great amount of information stored in publications that do not have associated, archived datasets, and in some cases, it may be possible to access that data using GIS. One example is published information about historical tree surveys. Primarily during the 1800s, the General Land Office divided most of the United States into townships that were subdivided into 36 sections, of $1.6 \mathrm{~km}$ (1 mile) squares. Surveyors recorded two to four tree species at section corners and halfway between section corners. These records provide 
47 information about forests before sustained Euro-American settlement and disturbance. Despite

48 availability of valuable ecological data that provide a record of historical forests, transferring

49 survey notes from the 1800 s to a more accessible format is time-intensive.

50 In Indiana, although survey notes were transcribed and analyzed by Potzger et al. (1956),

51 the data currently remain inaccessible, except in form of description, maps, and graphs. Potzger

52 et al. (1956) presented the approximately 214,500 trees surveyed between 1799 and 1846 in bar

53 chart format by township. To re-transfer data from the historical tree surveys to a GIS layer, with

54 current methods, would take about 1000 working days at about one township per day, if survey

55 notes are relatively legible. Librarians at Butler University (Potzger collection) and Purdue

56 University (Lindsey papers) were not able to locate any paper copies containing data tables of

57 tree surveys.

Potzger et al. (1956) summarized in bar graph format only the five most common species

or genera of American beech (Fagus grandifolia), oaks (i.e., primarily white oak, Quercus alba, but also including black oak, Q. velutina, northern red oak, Q. rubra, bur oak, Q. macrocarpa, chestnut oak, Q. prinus), sugar maple (Acer saccharum), upland ash (primarily white ash,

62 Fraxinus americana), and hickories (Carya spp.). Unlike current forests, many historical forests in the United States were dominated by oaks, pines, or beech, so that information about beech and oaks alone is sufficient to describe forests (Hanberry and Nowacki 2016). Even though exact composition of the approximately 80 tree species (Potzger et al. 1956) present historically in Indiana remains unknown, species other than oak and beech were minor ( $2 \%$ to $10 \%$ of all trees;

67 i.e., hickories, sugar maple, and upland ash ) to trace $(<2 \%)$ components of historical forests at

68 landscape scales. Thus, where beech and oaks were not dominant, they typically were present 
with many relatively uncommon species (Blewett and Potzger 1950; Potzger and Potzger 1950; Potzger et al. 1956; Lindsey 1961).

Data in a bar chart format are not useable for other applications, beyond providing a general description, while tabular data are useful, particularly when associated with spatial location. My primary objective was to convert the bar charts presented by Potzger et al. (1956) into tree compositional values joined to a GIS layer of townships. I converted the graphs to a TIF file and then used a regression between lengths in the bar charts and tree composition percentages, using previous work that provided tables of tree composition for townships within six counties (Blewett and Potzger 1950 and Potzger and Potzger 1950), to predict composition for the state. I also present ecological information reconstructed from bar charts to validate the method and show the value of recovered data. The study will provide the only source of tree percentages in historical forests of Indiana available currently. This unique method may be helpful for retrieving other valuable datasets collapsed into figures that otherwise would be labor-intensive or impossible to duplicate.

Methods

I converted the PDF file of the bar graphs from Potzger et al. (1956) to a TIF file, which is recognized as a raster (ESRI ArcMap software v. 10.3.1, Redlands, CA; see Figure 1 for list of GIS processing steps). I extracted by attribute to select the dark colored bars (colors up to 190 on 255 color scale), converted the raster to a shapefile, and then dissolved to turn multipart features to singlepart (i.e., to make an outline of each bar; Figure 2). Because the bar graph contained information such as borders and township lines, I cut any extraneous shapes that intersected bars. To determine bar length (along x-axis; Figure 2), I added geometry attributes (extent option). 
91

92

93

94

95

96

97

98

99

100

101

102

103

104

105

106

107

108

109

110

111

112

113

To provide location, I assigned townships to each row. Because townships presented by Potzger et al. (1956) were simplified, I processed each row to make sure it was assigned to the correct township and range, or removed rows that were indeterminate. For example, townships along the southern river border were difficult to determine correct assignment because rows were offset to avoid placement on the river. I removed townships with no data and small irregular polygons, for example, along rivers, resulting in a final total of 1000 townships covering $8,875,100$ ha (of 9,427,100 ha). I used township and range to join table information to a Public Land Survey System shapefile, which is a spatially correct representation of townships and ranges.

I assigned species information to each row based on row order, provided by Potzger et al. (1956) in the bar graph legends (i.e., oak then hickory, or beech then maple then ash). For about 224 townships, there were $<3$ rows for the beech, sugar maple, and upland ash. I matched the correct species/genus for each row based on location relative to other rows. Because species/genus was difficult to match in isolated rows, I removed the few, small beech, sugar maple, or upland ash rows that represented isolated groves from eight prairie counties of Lake, Newton, Benton, Warren, Jasper, Starke, Pulaski, and White in the Northwest (Finley and Potzger 1952).

I used 40 townships, which were completely within county borders, with known beech, sugar maple, upland ash, oaks, and hickories percentage composition from Blewett and Potzger (1950) and Potzger and Potzger (1950) for a regression (SAS, version 9.4, Cary, North Carolina; Proc Reg). I regressed percentage against row length to calculate a relationship between percentage and row length $\left(\mathrm{R}^{2}=97 \%\right)$. I then used the relationship to predict percent composition for each unknown row length. 

to an independent dataset of four complete townships from a GIS layer of GLO tree surveys for the Hoosier National Forest in central southern Indiana (available from the Hoosier National

117 Forest). To compare to written descriptions and maps (presettlement vegetation map by Lindsey et al. 1965; Generalized Presettlement Vegetation Types of Indiana, Circa 1820, Indiana Department of Natural Resources; http://maps.indiana.edu/previewMaps/Environment/Land_Cover_Presettlement_IDNR.html), I distinguished prairie and oak savannas based on Potzger et al. (1956) and classified forest type by identifying any species or genera that was greater than $24 \%$. If no species or genera was greater than $24 \%$, then I distinguished the forest type as eastern broadleaf forest, although this may indicate both swamps and upland forests. 1981-2010 at $800 \mathrm{~m}$ resolution (PRISM; http://www.prism.oregonstate.edu) and an elevation layer (10 m NED; https://lta.cr.usgs.gov/NED) and derived elevation variables (e.g., slope soil values (Miller and White 1998; http://www.soilinfo.psu.edu/index.cgi?soil_data\&conus\&citation) related to water availability: percent clay, available water capacity, permeability, hydrologic soil groups, soil texture class, porosity, and plasticity. I summed values for the soil layers and calculated mean values for each

133 forest type to determine if there was a strong underlying pattern missed by Lindsey et al. (1965). 134 Results To validate regression predictions (regression $\mathrm{R}^{2}=97 \%$ ) against another dataset, I 136 compared predictions to four complete townships in a GIS layer of GLO surveys for the Hoosier 
137 National Forest. Mean absolute error and root mean square error for predicted values compared

138 to observed values were 2.75 and 3.34 for beech, 1.97 and 2.61 for oaks, 2.49 and 2.64 for

139 hickories, and 3.38 and 3.84 for sugar maple ( $<1$ for ash). Furthermore, tree composition in

140 Hoosier National Forest matched forest classifications.

141 Maximum predicted composition values by township for oaks ( $99 \%$ of all trees), beech

142 (82\%), hickories (42\%), sugar maple (42\%), and ash (17\%) closely matched maximum values

143 listed by Potzger et al. (1956) of 98\% composition for oak, 80\% for beech, hickories and sugar

144 maple never exceeded $40 \%$ composition in any township, and upland ash never exceeded $19 \%$ in

145 any township. Overall, for 983 townships excluding 17 prairie townships, oaks were $27 \%$ of all

146 trees (area-weighted mean), beech was $25 \%$, hickories and sugar maple were $7 \%$ each, and ash

147 was $4.5 \%$. The other approximately 80 species (Potzger et al. 1956) accounted for 29.5\% of all

148 trees.

In this study, beech and/or maple forests dominated (i.e., $>24 \%$ of all trees) $48 \%$ of the state (Figure 3), while Potzger et al. (1956) identified 39\% beech-maple-ash forests and the

151 presettlement vegetation map by Lindsey et al. (1965) contained 50\% beech forest area.

152 Excluding oak openings, oak forests dominated 31\% of the state, while Potzger et al. (1956) identified 28\% oak forests and the map by Lindsey et al. (1965) contained 30\% oak forest area.

154 Oaks were present throughout the state, except in the northwestern prairie portion, and a few 155 isolated townships, resulting in 95 townships of 1000 townships without oak. Beech was present throughout the state, except in the northwestern prairie portion and southwestern portion, or 179

157 townships total without beech. The presettlement vegetation map by Lindsey et al. (1965)

158 generally matched forest types classified in this study (Figure 3;

159 http://maps.indiana.edu/previewMaps/Environment/Land_Cover_Presettlement_IDNR.html). 
160 Lindsey et al. (1965) classified beech-maple and oak-hickory forests based on if one had twice

161 the importance value of the other; otherwise, forests were classified as beech-oak-maple-hickory.

162 The beech-oak-maple-hickory forest type did not match with forests in this study. Also, prairies

163 and wetlands were more extensive than indicated by Potzger et al. (1956), which were used in

164 this study.

165 Although the more eastern distribution of beech suggests potential for greater

166 precipitation, 30 year mean precipitation was $107 \mathrm{~cm}$ for oak forests and $107.5 \mathrm{~cm}$ for beech

167 forests. The lowest value was for prairie at $97 \mathrm{~cm}$, followed by oak openings at $100 \mathrm{~cm}$. Oak-

168 beech, oak-hickory, and beech-maple forests averaged 110-113 cm. Oaks and beech were

169 dominant in both the flat north and central portions of Indiana, as well as the more dissected

170 south. Beech generally was located on moderately wet values for soil variables, but there were

171 exceptions where beech ranged onto other soils, while wetter soil values spread beyond the

172 border of beech distributions to where oaks and prairie also occurred (Figure 4). Mean value for

173 available water capacity was 16.3 for oak forests and 17.6 for beech forests, but oak-beech

174 forests had the lowest value of all forest types at 15.1. Sugar maple forests had the same value as

175 oak forests, while prairies were about the same as beech forests and oak-hickory forests had

176 greater values (18.4).

177 Discussion

178 It was possible to convert previously published bar charts of historical composition of

179 historically dominant tree species or genera in Indiana (Potzger et al. 1956) to an accessible GIS

180 layer. Despite the poor quality of the original figure (Potzger et al. 1956), the TIF image was

181 clear as a GIS layer (Figure 2). To my knowledge, although this method is relatively simple,

182 there is no documentation of previous use of GIS to recapture data condensed to bar chart format 
183 in publications that do not have archived raw data. Indeed, many current publications do not

184 have associated datasets. The need to reconstruct data from figures also emphasizes the

185 importance of sharing and archiving data, and the developed GIS layer for this study will be

186 archived. This method may be valuable to retrieve a variety of databases published in formats

187 that are not archived or otherwise accessible.

188 There were numerous sources of agreement between values recovered from bar charts

189 and reported or independent data. There was a strong relationship $\left(\mathrm{R}^{2}=97 \%\right)$ between length of

190 rows in bar graphs presented by Potzger et al. (1956) and compositional table values in Blewett

191 and Potzger (1950) and Potzger and Potzger (1950). Mean percentage differences between

192 predictions and observed values from an independent dataset transcribed for the Hoosier

193 National Forest were about 2\% to 3\%. Maximum predicted values by township closely matched

194 maximum values listed by Potzger et al. (1956; 99\% compared to 98\% for oaks, $82 \%$ compared

195 to $80 \%$ for beech, $42 \%$ compared to $40 \%$ for hickories and sugar maple, and $17 \%$ compared to

$19619 \%$ for ash). Forest types and areal extent generally agreed with Potzger et al. (1956) and the

197 presettlement vegetation map by Lindsey et al. (1965).

198 Recovered ecological information

199 Use of this method allowed reconstruction of historical composition by species, both

200 spatially in a GIS layer and by state. Indiana is a relatively large state, and inclusion of 8.9

201 million ha of historical species composition will assist on-going efforts to piece together

202 information about historical forests of the eastern United States (Hanberry and Nowacki 2016).

203 Information about where both oak and beech were dominant particularly may be helpful to

204 understand historical forests. 
hickories and sugar maple were 7\% each, and ash was $4.5 \%$. Beech and/or oak forests (i.e., $>24 \%$ of all trees) dominated $83 \%$ of townships, or $84 \%$ of 8.875 million ha due to township area irregularity. Although there were no species/genera $>24 \%$ of all trees in 92 townships, 36 of these 92 townships contained either beech or oak percentage $>20$. Sugar maple and hickories, which were the third and fourth most common tree species or genera (Potzger et al. 1956), were dominant alone in seven townships combined, or $0.7 \%$ of all townships. Hickories often are associated with oaks while sugar maple is associated with beech, and yet, historically, hickory and sugar maple abundance was secondary to oak and beech predominance. Indeed, in beechdominated forests (mean of $44 \%$ of all trees), oaks ( $8 \%$ ) were as common as sugar maple (8\%), with hickories and ash at around 5\%. Likewise, in oak-dominated forests (mean of 51\% of all trees), beech (6\%) was just slightly less abundant than hickories (9\%). locations, oaks and beech may have remained separated spatially by local moisture conditions, at

219 least in topographically variable sites. For example, beech was present on wetter north-facing slopes while oaks were present on drier south-facing slopes (Potzger et al. 1956); however, Whitney (1982) was not able to determine this relationship in northeastern Ohio. Similarly,

222 beech were present in protected valleys or on lower slopes while oaks were present on drier and more exposed ridges and upper slopes (Whitney 1982; Cowell and Hayes 2007). As for soils,

224 Whitney (1982) found that beech were associated with imperfectly drained soils from fine- 
At a coarser scale of townships and rather than individual trees, the separation of oak and

228

229

230

231

232

233

234

235

236

237

238

239

240

241

242

243

244

245

246

247

248

249

beech forests may be difficult to explain using precipitation or soil moisture based on topography and associated soils. Precipitation values were approximately $107 \mathrm{~cm}$ in historical beech and oak forests, albeit using modern precipitation values for 1981-2010, which are available at $800 \mathrm{~m}$ appropriate for resolution within states. Both beech and oak forests were dominant in the flat topography of northern Indiana and the more dissected topography of southern Indiana. Beech forests overall were restricted to moderately wet soils, with exceptions (Figure 4). Nonetheless, moderately wet soils were abundant in Indiana and the eastern US and extended to where oaks, prairie, and other forest types were present, rather than restricted to beech distributions. Lindsey et al. (1965), after extensive comparison between soils and forest types, were not able to isolate forest types based on soils.

Fire was near-annual in prairie states of the central US and in the southeastern US and became less frequent to the east and north (Day 1953; Fowler and Konopik 2007). Guyette et al. (2003) quantified a 23 year mean fire interval between 1650 and 1820 near the Ohio River in southern Indiana. Frequent surface fires favored prairies, open forests of savannas and woodlands, and fire-tolerant upland oak species (Hanberry et al. 2014). Whitney (1982) noted that fire was recorded in $<1 \%$ of surveyor records for three counties in Ohio along the border between beech- and oak-dominated forests. However, $67 \%$ of fire records occurred in $14 \%$ of townships, which were centers of Native American activity. In Indiana, the Wabash

Confederacy, for example, probably cleared land through girdling and fire for use along the Wabash River (Butler 1895). Butler (1895) wrote about prairies and open forests filled with American bison (Bison bison), particularly along river valleys and near West Lafayette (i.e., Ouiatanon) in Indiana, and into Kentucky prairies. 
Although oaks in general were the dominant genera (53\% of all trees) for the ecological

251

252

253

254

255

256

257

258

259

260

261

262

263

264

265

266

267

268

269

270

271

272

region of the central eastern United States (Hanberry and Nowacki 2016), there also were conditions that favored beech forests interspersed with oak forests. In addition to areas at fine scales that were protected from fire by water, wetlands, moist soils, rugged topography, and rocky outcrops, perhaps fire-protected conditions at landscape scales interacted with reduced or localized Native American fire regimes to produce larger landscapes where fire was less frequent. Butler (1895) stated that southeastern Indiana was not settled by American Indian villages, unlike western Indiana along the Wabash River and northeastern Indiana. Central and eastern Indiana thus appeared to be one such stronghold where fire protection allowed beech forests, with some continuity into Ohio, but surrounded to the north, west, and south by oak forests, woodlands, savannas, and prairies.

Conclusions

Data published during the 1900 s may no longer be effectively available except in figures. I applied GIS to recapture historical data contained in the length of hundreds of column bars in two figures from a 1956 publication. Use of GIS to recover information compressed into figures, with lengths that represent values, is a method that can be applied to other publications where data have been lost.

Acknowledgements

I thank P. Hanberry for GIS assistance and anonymous reviewers. This paper may not reflect views of the USDA Forest Service.

References

Blewett, M.B., and Potzger, J.E. 1951. The forest primeval of Marion and Johnson Counties, Indiana, in 1819. Butl. Univ. Bot. Stud. 10, 40-52. 
273 Butler, A.W. 1895. Indiana: a century of changes in the aspects of nature. Proc. Indiana Acad.

$274 \quad$ Sci. 5, 31-42.

275 Cowell, C.M., and Hayes, J.J. 2007. Structure, history and dynamics of a mature oak-beech

276 forest in western Indiana. J. Torrey Bot. Soc. 134, 215-222.

277 Day, G.M. 1953. The Indian as an ecological factor in the northeastern Forest. Ecology 34, 329$278 \quad 346$.

279 Finley, D., and Potzger, J.E. 1952. Characteristics of the original vegetation in some prairie $280 \quad$ counties of Indiana. Butl. Univ. Bot. Stud. 10, 114-118.

281 Fowler, C., and Konopik, E. 2007. The history of fire in the southern United States. Hum. Ecol. 282 Rev. 14, 165-176.

283 Gregory, I.N., Healey, R.G. 2007. Historical GIS: structuring, mapping and analysing 284 geographies of the past. Prog. Hum. Geogr. 31, 638-653.

285 Guyette, R.P., Dey, D.C., Stambaugh, M.C., 2003. Fire and human history of a barren-forest 286 mosaic in southern Indiana. Amer. Midl. Natur. 149, 21-34.

287 Hanberry, B.B., and Nowacki, G.J. 2016. Oaks were the historical foundation genus of the east288 central United States. Quat. Sci. Rev. 145, 94-103.

289

Hanberry, B.B., Jones-Farrand, D.T., and Kabrick, J.M. 2014. Historical open forest ecosystems 290 in the Missouri Ozarks: Reconstruction and restoration targets. Ecol. Restor. 32:407-416.

291 Lindsey, A.A. 1961. Vegetation of the drainage-aeration classes of northern Indiana soils in 292 1830. Ecology 42, 432-436.

293 Lindsey, A.A., Crankshaw, W.B., Qadir, S.A., 1965. Soil relations and distribution map of the 294 vegetation of presettlement Indiana. Bot. Gaz. 126, 155-163. 
295 Miller, D.A., and White, R.A. 1998. A conterminous United States multilayer soil characteristics 296 dataset for regional climate and hydrology modeling. Earth Interact. 2, 1-26.

297 Potzger, J.E., and Potzger, M.E. 1950. Composition of the forest primeval from Hendricks

298 County southward to Lawrence County, Indiana. Proc. Indiana Acad. Sci. 60:109-113.

299 Potzger, J.E., Potzger, M.E., and McCormick, J. 1956. The forest primeval of Indiana as

300 recorded in the original U.S. land surveys and an evaluation of previous interpretations of 301 Indiana vegetation. Butl. Univ. Bot. Stud. 13, 95-111.

302 Whitney, G.G. 1982. Vegetation-site relationships in the presettlement forests of northeastern 303 Ohio. Bot. Gaz. 143, 225-237. 
304 List of Figures

305 Figure 1. Flow chart of GIS steps.

306 Figure 2. Magnified image of original bar graph from Potzger et al. (1956) as a GIS layer (A)

307 and example of row length measurements (B).

308 Figure 3. Distribution of historical ecosystem types in Indiana.

309 Figure 4. Distribution of historical oak (A) and beech (B) forests overlaid on available water 310 capacity.

311

312 
Figure $\mathbf{1}$ (on next page)

Flow chart of GIS steps. 
2. Extract by attribute to select dark colored bars (colors up to 190 on 255 color scale)

3. Convert raster to a shapefile

4. Dissolve to turn bar multipart features to singlepart

5. Cut any extraneous shapes that intersect bars

6. Add geometry attributes (extent option) to measure bars

7. Assign species and township (spatial location) information to each bar in attribute table

8. Check data, correct or remove errors

9. Regression between bar lengths and represented values

10. If data are spatial, join to spatial shapefile

11. Validate results with independent or reserved data or written summaries. 


\section{Figure 2 (on next page)}

Magnified image of original bar graph from Potzger et al. (1956) as a GIS layer (left panel) and example of row length measurements (right panel). 

Figure 3 (on next page)

Distribution of historical ecosystem types in Indiana. 
Peeprairie

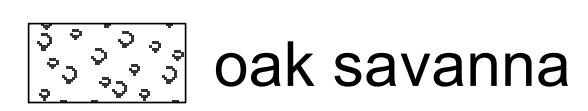

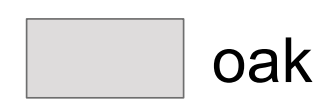

IIIII/ oak-hickory
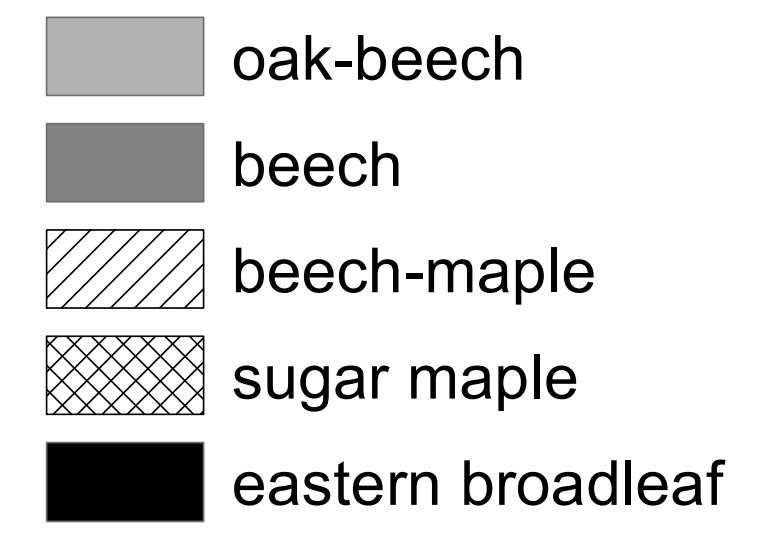

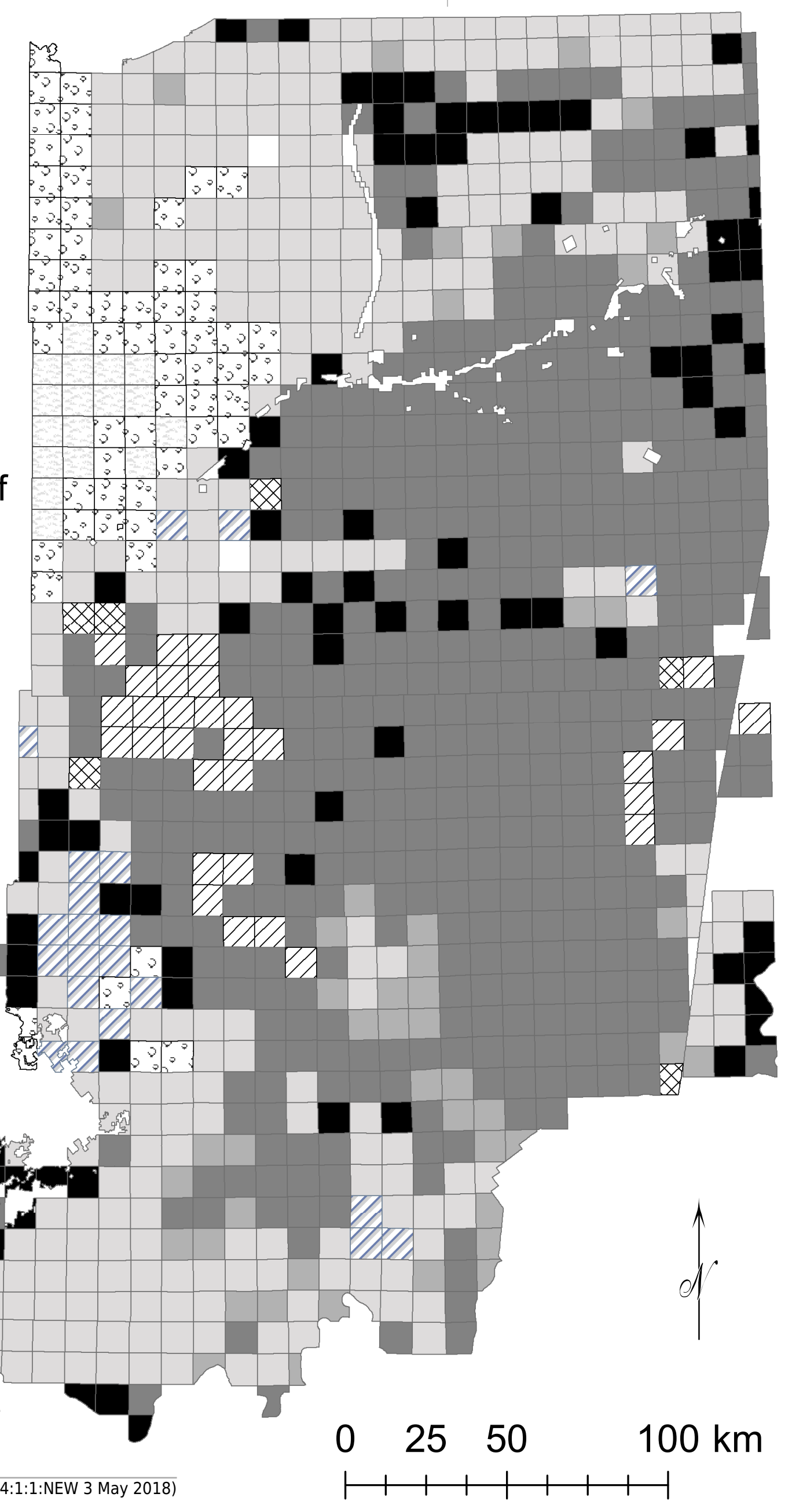


Figure 4 (on next page)

Distribution of historical oak (A) and beech (B) forests overlaid on available water capacity. 


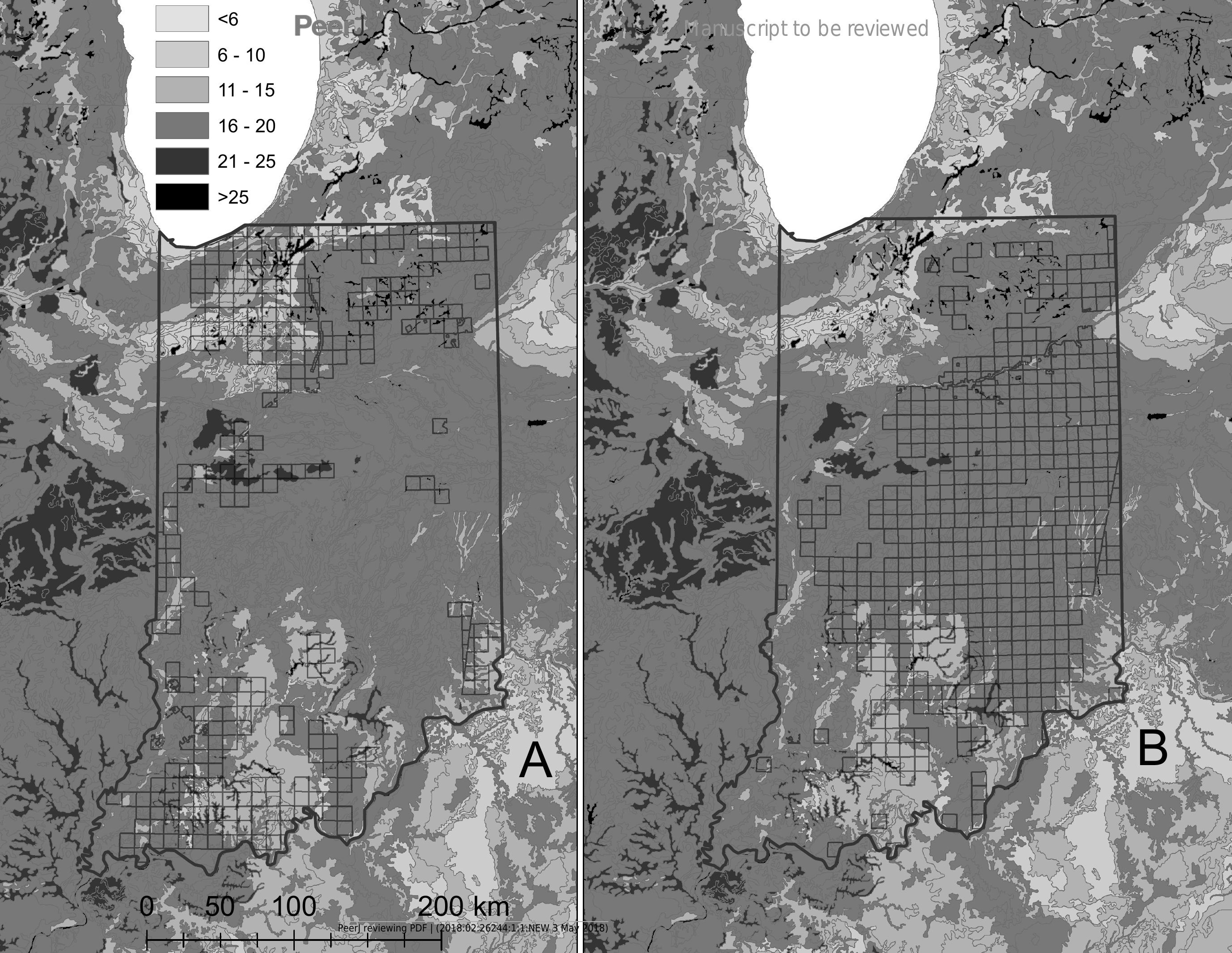

